\title{
Controvérsias midiatizadas no Twitter durante transmissões televisivas ao vivo: a rede "exoesqueleto" na abertura da Copa 2014
}

\author{
Mediatized controversies in Twitter during live television: \\ the "exoskeleton" network in the 2014 FIFA World Cup opening ceremony
}

\section{Carlos Frederico de Brito d'Andréa}

Doutor em Estudos Linguísticos (PosLin/UFMG) e mestre em Ciência da Informação (PPGCI/UFMG). Professor do Programa de Pós-Graduação em Comunicação Social (PPGCOM) e do Departamento de Comunicação (DCS) FAFICH/Universidade Federal de Minas Gerais (UFMG).

<carlosfbd@gmail.com>

\section{RESUMO}

No artigo discutimos a formação de redes emergentes de retweets (RTs) em conexão com transmissões televisivas ao vivo e a midiatização de controvérsias sociotécnicas a partir dos debates no Twitter. Ancorados na teoria Ator-Rede, consideramos as redes como um conjunto de associações e ressaltamos a importância de estudá-las em uma perspectiva temporal. A repercussão no Twitter da demonstração do exoesqueleto BRA-Santos Dumont, na abertura da Copa 2014, é o estudo de caso, que se baseia em um dataset de 25.115 RTs. Inspirados pela Cartografia de Controvérsias e considerando as especificidades das ambiências digitais, propomos dois movimentos de análise, com destaque para um vídeo e uma sequência de grafos que evidenciam as associações (RTs) ao longo da transmissão.

\begin{abstract}
This paper discusses the emergency of retweets networks motivated by live TV transmissions. Based in Actor-Network Theory, the paper considers networks as result of assemblages and agencies that must be analysed in a temporal way, in opposition to a structuralist approach. It's also discussed how the debates on Twitter reconfigures previous sociotechnical controversies as well as how the mediatization of these controversies alters the methods used to study them. The case study is based in a dataset of 25.115 retweets collected in Twitter about the demonstration of an exoskeleton during 2014 FIFA World Cup opening ceremony. Two methodological approaches are proposed to analyse the subject of the debates and to show in a video and graphs how the RTs networks changed during the transmission.
\end{abstract}

\section{Introdução}

O ecossistema midiático contemporâneo é marcado pela proliferação de artefatos midiáticos, por uma diversificação de práticas e por influências mútuas entre as lógicas transmissiva e massiva de comunicação. Partimos da premissa que, mais do que promover a extinção de tecnologias e seus usos, a cultura da convergência os hibridiza e catalisa formas variadas de associação nas redes intermidiáticas articuladas por humanos (usuários, leitores, telespectadores...) e não-humanos (interfaces, algoritmos, artefatos etc.). Nesse contexto, é 
emblemática a crescente aproximação entre as transmissões audiovisuais, em especial as realizadas ao vivo, e o uso das redes sociais on-line, com destaque para o Twitter.

Neste artigo nos voltamos para a dinâmica de formação de redes de retweets (RTs) a partir de transmissões televisivas de grande audiência. Em outras questões, nos interessa compreender como essas redes de RTs se formam ao longo do tempo e como os debates desencadeados nas redes sociais online pela abertura da caixa-preta das transmissões ao vivo trazem à tona, resignificam e midiatizam controvérsias sociotécnicas. A repercussão no Twitter da exibição do exoesqueleto BRA-Santos Dumont na cerimônia de abertura da Copa do Mundo FIFA 2014 é o estudo de caso apresentado, que se baseia em um dataset de 25.115 retweets com o termo "exoesqueleto", coletados no dia 12 de junho de 2014.

Ancorados nas teorias Ator-Rede e dos Sistemas Adaptativos Complexos, iniciamos o artigo discutindo as redes como um conjunto de associações entre mediadores e intermediários, a partir da emergência de um processo potencialmente auto-organizado de debates, e, em seguida, discutimos as especificidades das redes de RTs no Twitter. Ao privilegiar a formação das redes, e não as estruturas delas, apontamos a importância de estudá-las em uma perspectiva temporal, o que nos impõe o desafio de procurar alternativas aos conceitos e parâmetros da Análise de Redes Sociais.

Compreendendo as controvérsias sociotécnicas como situações privilegiadas para o estudo de redes, discutimos em seguida as transformações dessa perspectiva advinda da Teoria Ator-Rede no processo contemporâneo de midiatização das agências e de hibridização dessas controvérsias com os ambientes midiáticos em que elas se efetivam.

Inspirados por metodologias recentes de cartografias de controvérsias baseadas na extração e visualização de dados, propomos dois movimentos de análise da subcontrovérsia "Exoesqueleto-TV Globo-FIFA": 1) caracterização dos debates e dos atores que agem nas redes de RTs do Twitter e; 2) análise das associações através de uma rede temporal, com destaque para o período de uma hora e meia entre a rápida exibição do exosqueleto na cerimônia de abertura e as repercussões da reprise das imagens pela TV Globo (supostamente em função da pressão das redes sociais on-line).

Este trabalho é fruto de um projeto de pesquisa em curso no PPGCOM/ UFMG e que se volta para o estudo das conexões intermidiáticas entre emissões 
audiovisuais ao vivo e redes sociais online durante dois eventos programados: a Copa do Mundo e as eleições presidenciais ${ }^{1}$.

\section{Redes sociotécnicas em ambientes midiáticos}

Em trabalho anterior (D’andréa, 2014), caracterizamos três tipos de conexões intermidiáticas: 1) iniciativas institucionais de canais de televisão (por exemplo, aplicativos de "segunda tela"); 2) formas auto-organizadas de conversação online que problematizam e resignificam transmissões ao vivo, fazendo emergir sistemas de respostas e controvérsias; e 3) novas formas de transmissão audiovisual via internet (streaming) que se constituem de forma indissociável das redes sociais online. Retomamos no presente artigo algumas considerações que partem desse segundo modelo de conexão intermidiática, que se caracteriza por um tensionamento entre a preservação da televisão como uma "mídia regente" (Fechinne, 2013) que direciona as redes sociais online e um potencial processo auto-organizado que, à revelia de um "controle externo" (De Wolf e Holvoet, 2005), pode culminar na emergência de um ambiente mais intenso e plural de debates. Um movimento auto organizado da audiência conectada através do Twitter (ou outros ambientes) pode ser visto como um "sistema emergente de resposta" da sociedade à mídia (D'andréa, 2011 e 2014) e/ou como um ambiente rico em controvérsias sociotécnicas, conforme retomaremos adiante.

As transmissões ao vivo de eventos por emissoras de TV são uma "experiência festiva" (Dayan e Katz, 1995) que, em oposição à crescente fragmentação e segmentação dos hábitos de consumo audiovisual (Fechinne, 2013), agregam uma grande quantidade de espectadores simultâneos, constituindo uma audiência conectada. Essa visibilidade e mobilização atingem níveis máximos em eventos de escala mundial, como na transmissão dos megaeventos esportivos e, em especial, de suas cerimônias de abertura. Resultado de um minucioso e crescente processo de planejamento e roteirização (Jost, 2007), esses eventos midiáticos planejados funcionam como uma caixapreta que esconde complexas redes sociotécnicas. Nesse arranjo, muitas vezes

1 O projeto "As webTVs em conexões intermidiáticas: redes sociotécnicas na cobertura jornalística de dois eventos programados" é financiado pelo CNPq (Edital Universal 14/2013), pela Fapemig (Demanda Universal 2013) e PRPq/UFMG (Programa Institucional de Auxílio à Pesquisa de Doutores RecémContratados). Compõem a equipe de pesquisa os bolsistas de IC Fapemig Leonardo Melgaço, Marco Túlio Guimarães e Marina Novais, a quem o autor agradece pelo apoio e interlocução. A coleta de dados no Twitter foi realizada em parceria com o grupo de pesquisa MTPLNAM/ UFVJM. Agradecemos ainda ao Labic/UFES pelo apoio técnico. 
algo na transmissão escapa do planejado e a caixa-preta se abre, escancarando processos invisibilizados e desencadeando novas redes através da audiência conectada, o que complexifica o processo planejado de brodcasting.

Adotando a perspectiva da Teoria Ator-Rede, assumimos como rede um conjunto de associações desencadeadas pela agência de humanos e nãohumanos a partir da capacidade desses de transportar, de deslocar, de fazer circular (Callon, 2008) diferentes tipos de elementos materiais ou simbólicos. Assim, a dinâmica e a extensão de uma rede depende, entre outros fatores, da capacidade dos agentes de transladar uns aos outros, isto é, convencer, influenciar, mobilizar, deslocar, criar vínculos (Crawford, 2004; Latour, 2001). Essa dinâmica se dá pela articulação das agências daqueles que estão (e não são, uma vez que os papéis estão em constante modificação) atuando como intermediários e mediadores. Conforme Callon (2008, p. 150), um intermediário "é qualquer coisa que passa de um ator a outro e que constitui a forma e substância da relação estabelecida entre eles", enquanto um mediador se destaca por sua capacidade de transformar a rede, ou de colocar outros intermediários em circulação. Assim, enquanto um intermediário permite a ligação entre dois outros agentes, o mediador é aquele que age e, principalmente, provoca a ação de outros, desencadeando um processo de translação que, em última instância, garante a dinamicidade da rede em formação.

Em um ambiente como o Twitter, incontáveis redes de associações entre agentes humanos e não humanos se formam simultaneamente. A timeline de um usuário, por exemplo, pode ser lida como uma rede que funciona como um texto personalizado sobre assuntos variados. Já as hashtags são recursos fundamentais para fomentar comunidades ad hoc (Bruns e Burgess, 2011) interessadas em se juntar a uma conversação temporária sobre um tema. Voltamo-nos aqui, no entanto, para um recurso do Twitter que contribui para a formação de outras redes nesse ambiente: os retweets. O recurso RT (oficializado, desde 2009, através de um botão presente nas diferentes interfaces) pode ser visto como um intermediário que põe em relação dois perfis do Twitter, efetivando uma translação entre o mediador (A) que postou a mensagem "original" e foi tomado como um porta-voz por outro agente $(B)^{2}$.

2 As mensagens repassadas através do "retweet automático" são encaminhadas na íntegra através do botão "RT" do Twitter. Assim, exibido para os seguidores de (B), o tweet de (A) pode ser repassado por (C), (D) etc., mantendo, no entanto, seu formato inicial, o que inclui a referência apenas ao autor (A). Nas redes de RTs, portanto, as translações em sequência resultam na expansão de uma rede que envolve diferentes perfis mas deixa como rastro apenas a associação deles com o mediador que postou pela primeira vez o tweet em questão. Já os "retweets editados" são considerados novas mensagens, que por sua vez podem ser retuitadas e são contabilizadas separadamente. 
Considerando que "a ação nunca é propriedade de um actante, mas de uma rede" (Lemos, 2013, p. 45), isto é, que a força de um agente está na sua capacidade de ser um ator-rede, a força dessas cadeias de translações está na possibilidade dos perfis mediadores provocarem outros a agir (isto é, também retuitar), alavancando redes mais extensas e complexas. Em última instância, essa dinâmica contribui para uma negociação em torno de temas e pontos de vista de maior visibilidade no Twitter e em seus desdobramentos intermidiáticos.

É fundamental observarmos que, por não estarem dadas a priori, as redes se formam com o passar do tempo, isto é, é o desencadear de agências ao longo de um período que efetiva uma rede que se caracteriza por movimentos e transformações, o que diferencia a abordagem da Teoria Ator-Rede da Análise de Redes Sociais (ARS) (Venturini, 2013). Por enfatizar a mobilidade dos agentes durante a formação das redes sociotécnicas, o estudo das redes temporais (Holme e Saramaki, 2012) pode ser visto como uma alternativa a uma perspectiva estruturalista de estudo de redes. Para identificar padrões sociais a partir das interações entre os atores, a Análise de Redes Sociais (ARS) apropria-se da representação visual de grafos estáticos que podem ser vistos como uma "fotografia" que mostra a soma de associações entre os agentes. Já uma rede temporal pode ser encarada como um filme, isto é, uma sequência de situações que mostra os encadeamentos das associações de modo a enfatizar o que acontece com o passar do tempo. Em especial no caso do Twitter, a ausência de algoritmos sociotécnicos que rehierarquizam as timelines dos usuários e reorganizem sua lógica temporal (como no Facebook) torna ainda mais importante a compreensão das redes em função do momento em que elas se formam, enfatizando o fluxo contínuo e não acumulativo de tweets exibidos a cada usuário.

\section{Controvérsias sociotécnicas midiatizadas}

Sendo o"social" algo construído, continuamente, a partir das associações entre os atores humanos e não humanos, ganham evidência as situações em que os coletivos de agentes estão em plena ação, ou seja, estão mobilizados em torno de uma controvérsia. Conforme Venturini (2010), há uma controvérsia quando os agentes reconhecem a ausência de consenso sobre um projeto e se engajam na publicização de seus argumentos com a intenção de convencer (ou traduzir, transladar) outros agentes. Nesse momento, a "caixa-preta" das associações está aberta e ficam evidenciadas as posições em torno de um assunto e os movimentos dos agentes, possibilitando o acompanhamento claro do jogo de forças em curso. 
Para Venturini e outros (2014), para cartografar uma controvérsia é preciso encapsular a complexidade de um debate sociotécnico em um atlas mais estável que a própria controvérsia, sem, no entanto, deixar de acompanhar a evolução e as transformações das questões em debate. Para tanto, propõem movimentos metodológicos que ao mesmo tempo desconstruam as controvérsias e as reconstruam em representações que deem conta de sua complexidade. Em síntese, Venturini e outros (2014) propõem que: 1) deve-se partir das declarações dos atores para se compreender o que se está debatendo; 2) dos debates voltase às declarações para identificar quem fala, isto é, quem são os mediadores e porta-vozes. 3) dos atores partimos em busca das redes a eles atreladas; 4) das redes deve-se cartografar as cosmoses, que são visões de mundo que articulam a controvérsia as meta-controvérsias e subcontrovérsias; 5) das cosmoses partese para a identificação das cosmopolíticas.

A multiplicação de rastros de associações sociotécnicas identificadas em ambientes digitais tem motivado a aproximação da Cartografia das Controvérsias com técnicas e perspectivas oriundas das ciências da computação e visualização de dados, entre outras áreas (Venturini; Jàcomy e Pereira, 2014). Ao discutir as especificidades de estudo das controvérsias em ambientes digitais, Marres (2015, p. 15) pergunta: "Estamos mapeando controvérsias ou efeitos das tecnologias de mídia?" Para a autora, se considerarmos que as tecnologias como parte das controvérsias online, é preciso estar atento à sua influência nas controvérsias públicas e à "ambiguidade inerente" dos objetos empíricos oriundos dessa relação, assim como considerar uma maior diversidade de atores e de atuações possíveis (ativismo, por exemplo).

Partindo de Marres (2015), reconhecemos uma hibridização entre as controvérsias sociotécnicas e os ambientes midiáticos em rede em que elas também se constituem e dos quais são extraídos dados para estudos. Trata-se de uma questão ao mesmo tempo conceitual e metodológica que podemos compreender à luz do crescente processo de midiatização da sociedade contemporânea (Heep, 2014). Nesse sentido, a agência dos mediadores engajados na formação do social não se dá apenas através da mídia, mas também a partir e em função dela - culminando na constituição de"controvérsias midiáticas" (Graeff, Stempeck e Zuckerman, 2014) -, o que torna inviável pensar as associações e translações contemporâneas fora das ambiências midiáticas.

Parece-nos pertinente então pensar em "níveis" de controvérsias em função de especificidades como sua duração, o escopo das negociações, a diversidade de agentes envolvidos, entre outros aspectos. Conforme Venturini e outros (2014), "todo tema controverso será sempre parte de outras 
metacontrovérsias mais amplas e sempre composta por várias subcontrovérsias menores". Nesse sentido, em casos específicos as redes sociotécnicas desencadeadas no Twitter a partir das transmissões televisivas ao vivo podem ser tratadas como subcontrovérsias localizadas que surgem de controvérsias e metacontrovérsias mais extensas e duradouras e potencialmente as resignificam em função da sua intensidade.

\section{Projeto Andar de Novo: uma controvérsia midiatizada}

O desafio do projeto Andar de Novo é o desenvolvimento de um exoesqueleto capaz de se comunicar através de sinais elétricos com o cérebro de um paraplégico, permitindo que a pessoa mova as pernas e ande. Baseado em pesquisas anteriores sobre interface cérebro-máquina, esse projeto iniciouse em 2009 com a meta de desenvolver um protótipo para dar o pontapé inicial da abertura da Copa do Mundo no Brasil. A iniciativa é coordenada pelo neurocientista Miguel Nicolelis, que, após anos de atuação destacada no exterior, liderou a implementação do Instituto Internacional de Neurociências Edmond e Lily Safra, em Natal (RN).

O projeto "Andar de Novo" parece preencher todos os requisitos de uma controvérsia sociotécnica. Entre as questões amplamente discutidas ao longo da execução do projeto, estão regulamentações éticas (pesquisa com animais e seres humanos), a viabilidade técnica do projeto (a inserção de eletrodos no cérebro foi substituída por uma toca de menor resolução) (Beguocci e Burgierman, 2014), a disputa entre cientistas (a discordância com o modelo de gestão de Nicolelis culminou em uma ruptura com sua equipe inicial, que veio a fundar o Instituto do Cérebro da UFRN) (Esteves, 2011), a relação entre políticopartidária e ciência (acusações de uso político do projeto pelos presidentes Lula e Dilma Rousseff) (Lemes, 2014) e uso de verbas públicas para Ciência e Tecnologia (os $\mathrm{R} \$ 33$ milhões concedidos pelo governo federal para o projeto Andar de Novo é um dos mais altos montantes já investidos em C\&T no país). Dentro os indícios de midiatização da controvérsia do projeto "Andar de Novo", está o destaque em publicações especializadas e generalistas, a centralidade atribuída a Miguel Nicolelis, que atua como um porta-voz da rede que mobiliza (Alves, 2014). Destaca-se ainda a intensa presença do neurocientista nas redes sociais online Twitter e Facebook.

A midiatização dessa controvérsia teve seu ápice programado para a abertura da Copa do Mundo FIFA 2014. O experimento foi uma das atrações da cerimônia que, para além do exoesqueleto, foi cercada de outras questões polêmicas intensificadas após as Jornadas de junho de 2013, como os gastos 
excessivos e o atraso na construção do estádio Itaquerão, a repressão às manifestações políticas em São Paulo e outras cidades, e vaias e xingamentos direcionadas pelos torcedores presentes no estádio à presidenta Dilma Rousseff. Segundo matéria veiculada no Portal da Copa, três dias antes do evento, o esperado era que um "paciente paraplégico" se levantasse de uma cadeira de rodas, caminhasse "por cerca de 25 metros" e desse o "primeiro chute da Copa" (Delmazo, 2014). O experimento, no entanto, foi exibido na TV durante apenas três segundos.

No caso da transmissão da TV Globo, o pouco destaque dado pela FIFA foi agravado pela decisão de dividir a tela segundos antes da exibição do exoesqueleto para mostrar a chegada do ônibus da seleção brasileira ao Itaquerão ${ }^{3}$. A emissora só voltou ao tema uma hora e 10 minutos depois, quando repetiu as imagens e ressaltou a importância da demonstração científica. $O$ mínimo destaque dado ao projeto Andar de Novo durante a transmissão da FIFA e, em especial, da TV Globo desencadeou um intenso processo de associações nas redes sociais on-line e repercutiu de forma significativa na cobertura de vários veículos jornalísticos, o que parece caracterizar uma subcontrovérsia que, em diálogo com as discussões anteriores em torno do projeto, tem especificidades em função da grande visibilidade atingida pela abertura da Copa do Mundo FIFA.

\section{Explorando a rede "exoesqueleto" no Twitter}

Dentre as várias possibilidades de análise empírica das repercussões no Twitter da demonstração do exoesqueleto, partimos de um dataset composto por tweets com a palavra "exoesqueleto". Usando as ferramentas yourTwapperKeeper e Hootsuite, foram coletados 36.112 tweets, entre 12h58 e 22h (horário de Brasília), do dia 12 de junho de 2014. Esse período de nove horas compreende uma possível repercussão sobre o tema antes do início da cerimônia, durante a mesma (o exoesqueleto foi exibido na TV por volta de 15h33) e ainda as repercussões posteriores - a TV Globo voltou ao tema às $16 \mathrm{~h} 41$ (pouco antes do jogo Brasil x Croácia) e o Jornal Nacional exibiu uma matéria sobre o exoesqueleto aproximadamente às 20h41. O dataset é composto por tweets em

3 O trecho da transmissão da Globo pode ser visto em $\leq$ http://t.co/NPj9g6VDJn>.

4 Uma falha interrompeu a coleta durante aproximadamente 13 minutos (entre 16h17 e 16h30). Esta limitação será considerada na análise dos dados. 
português e em espanhol. Após conversão com scripts Parse Tweets ${ }^{5}$, o dataset de 36.112 tweets deu origem a um grafo composto por 25.115 associações, ou seja, por $69,5 \%$ dos tweets coletados foram RTs.

Inspirados nos procedimentos propostos por Venturini e outros (2014) e Venturini,Jacomye Pereira (2014), propomosaqui doismovimentos deanálise das redes de RTs. Inicialmente procuramos identificar e categorizar as "declarações" presentes no tweets coletados. Seguindo uma instrução elementar da TAR ("ouvir os atores"), após uma incursão exploratória no dataset identificamos três grandes debates sobre o tema no período estudado, conforme detalhamos a seguir. Nesse primeiro movimento de análise, identificamos também "quem fala", isto é, os principais perfis do Twitter envolvidos na subcontrovérsia. No segundo movimento analítico, procuramos identificar através de uma rede temporal como as associações (RTs) entre os perfis se deram ao longo do período e se articulam com a transmissão televisiva. Para tanto, produzimos um vídeo que mostra as transformações na rede ao longo das nove horas coletadas e, em seguida, destacamos detalhes das associações efetivadas a cada 15 minutos entre $15 \mathrm{~h} 20$ e $17 \mathrm{~h} 05$.

O debate de maior visibilidade no Twitter durante o período estudado diz respeito à transmissão televisiva da cerimônia. Os tweets referentes a esse tema totalizam $57,05 \%$ dos RTs do dataset. Neste grupo estão redes de RTs que fazem críticas à transmissão televisiva, críticas direcionadas à TV Globo e conjuntos de RTs que enfatizam o "resultado" da pressão das redes sociais online sobre essa emissora. O segundo grande debate no Twitter (23,79\%) centrouse nas especificidades do projeto Andar de Novo. A maioria dessas redes de RTs procurou divulgar o projeto ou sua transmissão antes ou depois da transmissão, enquanto outras redes enfatizaram as virtudes ou fizeram críticas ao projeto. Bem mais heterogêneo, um terceiro conjunto de RTs reúne as redes que enfatizam a relação do projeto científico com outros temas ou controvérsias, como a falta de apoio à ciência no Brasil e as relações do projeto Andar de Novo com questões políticas que emergiram antes da Copa, como críticas à FIFA. Completa esse debate um conjunto de retweets irônicos que, entre outras questões, sugeriram a escalação do exoesqueleto para melhorar a desempenho da Seleção Brasileira no jogo de estreia da Copa.

O gráfico abaixo (gerado no Gephi com a distribuição Force Atlas mostra os nós (perfis) e arestas (RTs) que compõem o dataset em análise (Figura 1). Para

5 Script em python que realiza filtragem dos dados coletados gerando arquivos csv. Desenvolvido pelo Labic/UFES. Disponível em: <https://github.com/ufeslabic/parse-tweets >. 
enfatizar as associações, na visualização procuramos não dar grande destaque aos nós (o tamanho desses varia de 2 a 20, de acordo com o grau) e ressaltamos as arestas, que foram classificadas por cores de acordo com os debates aos quais se refere. As arestas em diferentes tons de vermelho correspondem ao debate sobre a transmissão; em verde, os RTs que enfatizam o projeto; e em azul estão os RTs que trazem outras perspectivas sobre o exoesqueleto.

Figura 1: Rede de RTs com o termo "exoesqueleto" entre $12 \mathrm{~h} 58$ e 22h, do dia $12 / 05 / 2014$

Fonte: Elaboração do autor

Visando conhecer melhor as associações dessa rede se efetivaram ao longo das nove horas coletadas, produzimos um vídeo com um minuto e 48 segundos de duração, que pode ser visto em $\leq$ http://youtu.be/B wdX26Jtu4 $>$. No vídeo, cada segundo corresponde a 5 minutos e, através de legendas, 
apontamos os momentos-chave da transmissão televisiva e/ou dos debates no Twitter ao longo das nove horas coletadas.

Voltamo-nos aqui para uma sequência específica da transmissão televisiva, que compreende o período de uma hora e meia entre a exibição do exoesqueleto e as repercussões da reprise pela TV Globo. Geramos grafos que correspondem a intervalos de cerca de 15 minutos cada ${ }^{6}$. A Figura 2 reúne 3018 retweets efetuados entre $15 \mathrm{~h} 35$ e 15h50, portanto, logo após a rápida aparição do exoesqueleto na TV (por volta de 15h33).

Figura 2: Rede de RTs com o termo "exoesqueleto" entre 15h35 e 15h50, do dia 12/05/2014

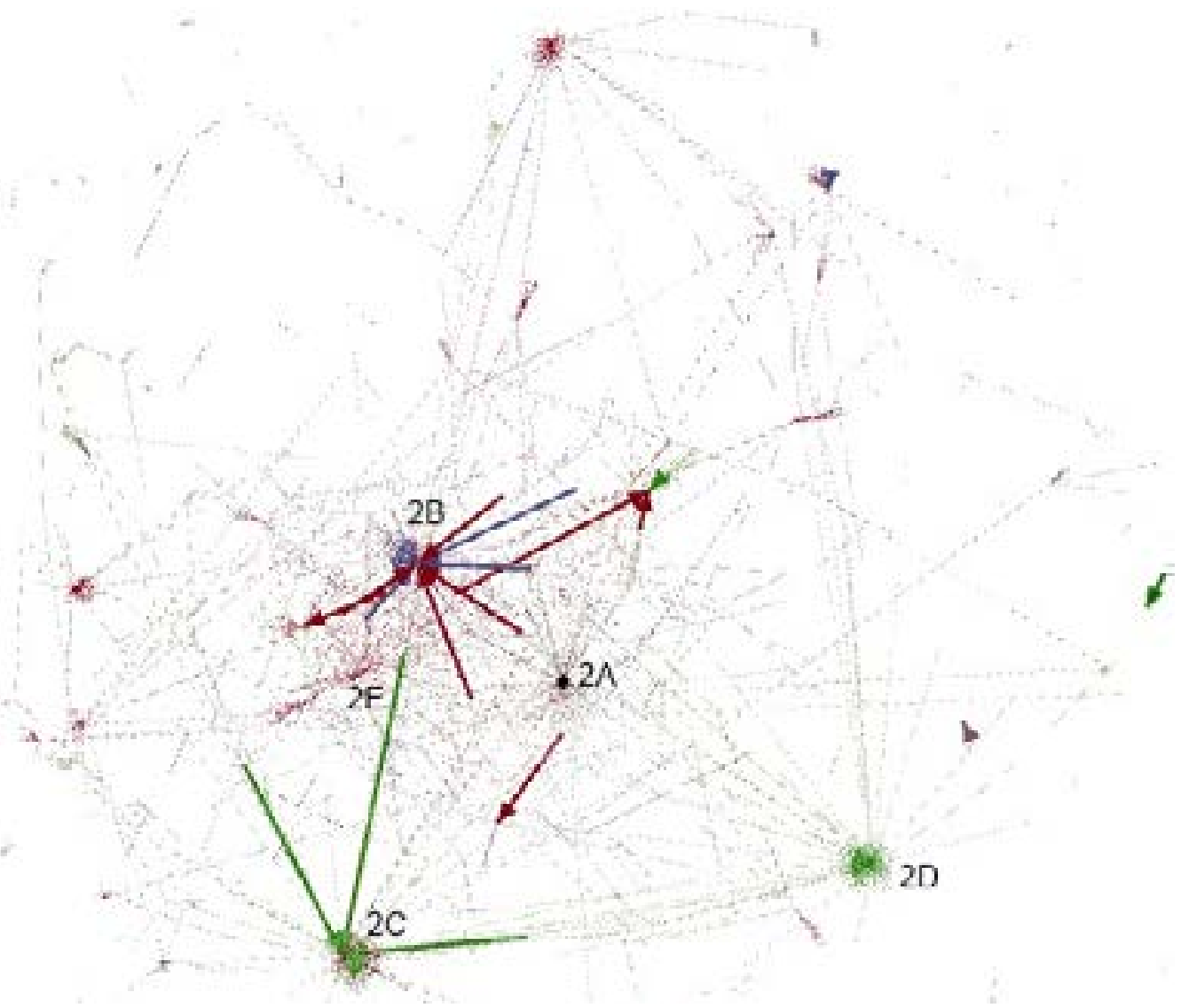

Fonte: Elaboração do autor

6 Como cada retweet coletado possui o dado relativo ao seu horário de postagem (rt.time), no softwares Gephi é possível visualizar intervalos específicos da rede manipulando o recurso "linha do tempo". 
Nessa imagem identificamos o início da emergência das associações em torno de alguns perfis. É o caso do conjunto $2 \mathrm{~A}$, que reúne os rastros iniciais de RTs do tweet de @vivacqua "Perdemos o pontapé do exoesqueleto pra ver o ônibus entrando na vaga e agora temos a Cláudia Leite fazendo playback"7. Esta rede de RTs se prolonga durante intervalos seguintes (ver Figuras 3 e 4), se efetivando como a mensagem mais retuitada do período analisado (2976 RTs) ${ }^{8}$. Outro destaque são as redes de RT em torno do perfil @impedimento (2B), que durante esse intervalo publicou três tweets sobre "exoesqueleto", entre os quais PERAÍ REFAZ A CERIMÔNIA QUE NINGUÉM VIU O EXOESQUELETO DIREITO?.

Ainda na Figura 2, chamam atenção duas redes de RTs de cor verde posicionadas de forma periférica no grafo. $\mathrm{O}$ conjunto $2 \mathrm{C}$ representa a rede de RTs do tweet“@VarskySports: \#Brasil2014 El momento del puntapié incial con el exoesqueleto <http://t.co/O7YqTsz9zP>" (postado às 15h44) e o conjunto 2D mostra as redes de RTs de dois tweets do perfil @todapasion. Essas mensagens em espanhol foram as primeiras a exibir uma foto do exoesqueleto chutando a bola à beira do gramado, minutos antes. A imagem foi reproduzida pouco depois, entre outros, por @calhau (conjunto 2E).

$\mathrm{Na}$ Figura 3, as 8.635 arestas coloridas indicam uma intensa emergência de associações no período entre $15 \mathrm{~h} 50$ e $16 \mathrm{~h} 05$ - esse total de RTs representa mais de um terço do dataset. Além de um prolongamento das redes de RTs iniciadas na figura 2, destacam-se as associações em torno de um novo tweet do perfil @ impedimento (3A), postado às $15 \mathrm{~h} 53:$ "E teve exoesqueleto mesmo. Lamentável o desprezo total da transmissão ao que deveria ter o principal destaque." (total de 1.004 RTs). Essa mensagem traz a mesma foto postada por @VarskySports e @todapasion, imagem esta que foi usada também pelos perfis @trivela (3B) e @ thiagosiqueiraf (3C), entre outros.

7 Não é possível identificar o horário do tweet porque ele foi apagado posteriormente.

8 A quantidade de RTs foi coletada no dataset fornecido, e não no número informado pelo Twitter nos tweets.

9 Em função do limite de caracteres do artigo, optamos por não inserir a URL dos tweets, que podem ser localizados na busca avançada do Twitter. 
Figura 3: Rede de RTs com o termo "exoesqueleto" entre $15 \mathrm{~h} 50$ e 16h05, do dia 12/05/2014

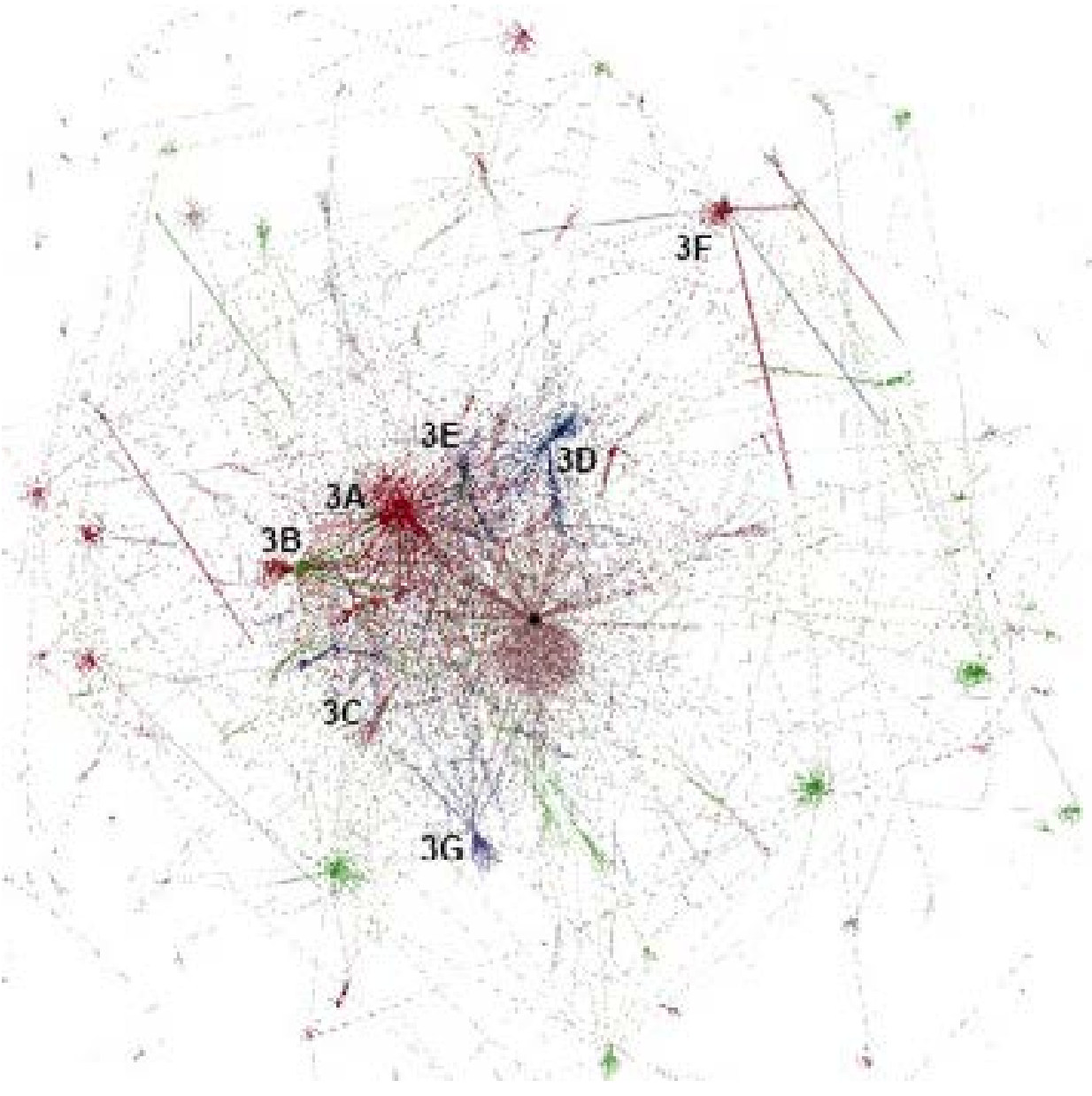

Fonte: Elaboração do autor

Dois tweets destacam-se por enfatizar a falta de apoio à ciência: @ trasel escreveu que "O espaço dado ao exoesqueleto do Nicolelis foi bem representativo da importância que o Brasil dá à ciência. Achei honesto", desencadeando uma rede de 488 RTs (3D), e @_fransuel tuitou MTO BOM O EXOESQUELETO UM PASSO CRUCIAL PRA CIENCIA GANHOU 2 SEGUNDOS NA TV (117 RTs, conjunto 3E).

Os retweets publicados entre $16 \mathrm{~h} 05$ e $16 \mathrm{~h} 20$ totalizam 5.264 arestas no grafo da Figura 4. Menos denso que o período anterior, essa imagem revela a continuação das redes de RTs desencadeadas pelos tweets já citados de @ vivacqua, @trasel e @impedimento. Emergem novas redes de RTs em torno dos tweets de @oficialjoao ("A Globo preferiu mostrar o ônibus entrando no estádio do q o chute do paraplégico com o exoesqueleto. Prioridades..") (4A) e, mais periférico, do tweet de @drogalizado ("Perdemos o chute do deficiente 
com exoesqueleto a globo achou importante mostrar o ônibus entrando no estádio!") (4B). Chama atenção a presença do perfil @G1 (4C), que em dois tweets (postados às $16 \mathrm{~h} 05$ e 16h12) divulgou a presença do exoesqueleto na abertura através um vídeo de cinco segundos extraído da transmissão da Globo e de um link para uma matéria do portal ressaltando, entre outras questões, a reclamação de Miguel Nicolelis quanto ao pequeno destaque reservado pela FIFA. Merecem atenção ainda as redes de 35 RTs em torno de @diogomainardi ("Exoesqueleto chutou Dilma mas ninguém viu") (4D) e as associações em torno do tweet do perfil fake @dilmabr ("Aguardando o pontapé inicial do moço usando o exoesqueleto... \#WorldCup \#Copa2014 \#VaiBrasil") (82 RTs, 4E).

Figura 4: Rede de RTs com o termo "exoesqueleto" entre $16 \mathrm{~h} 05$ e $16 \mathrm{~h} 20$ do dia 12/05/2014

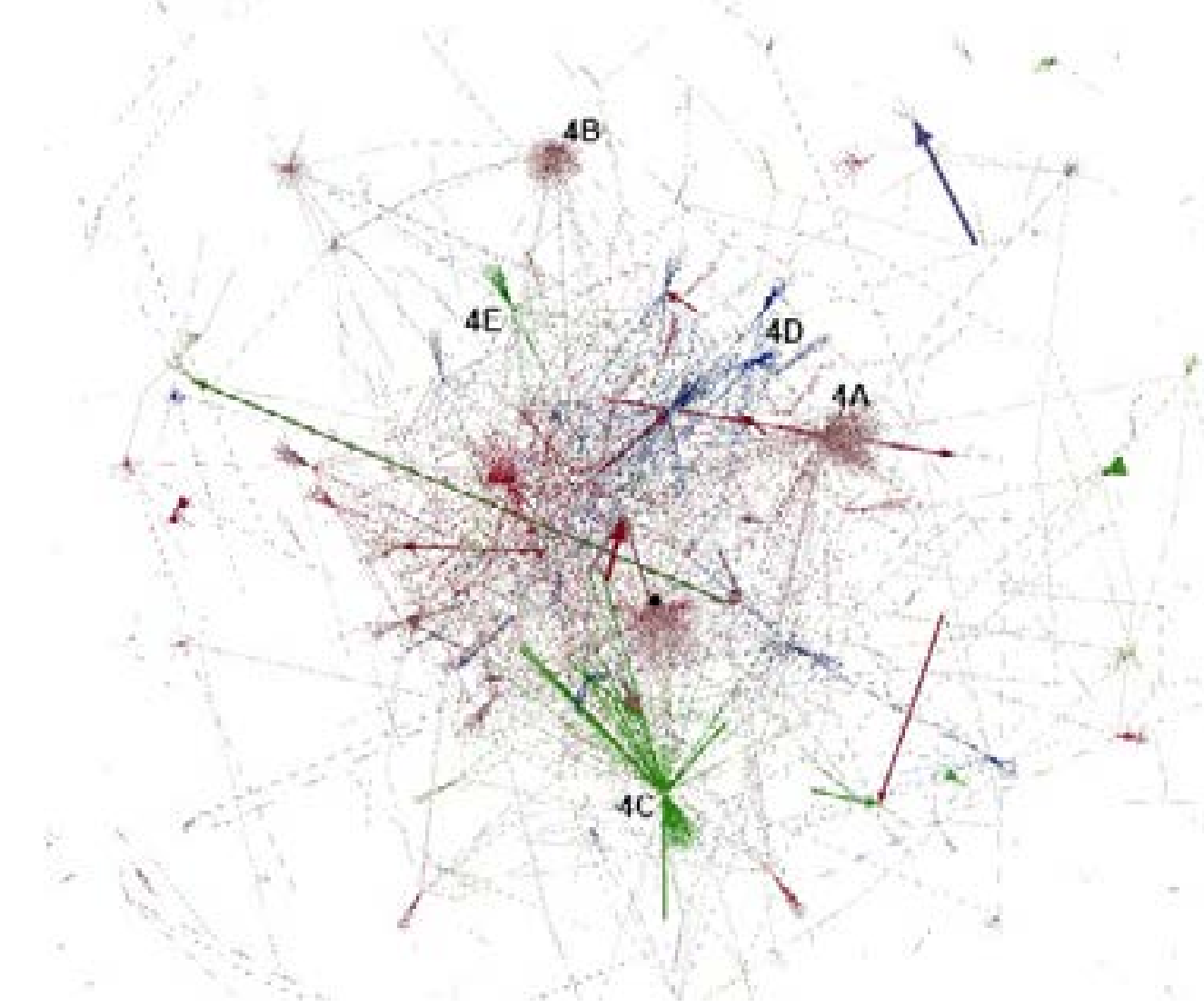

Fonte: Elaboração do autor

Em função de um erro na coleta dos dados, não foi possível gerar um grafo e fazer uma análise do intervalo entre 16h20 e 16h35.

No período seguinte (16h35 a 16h50) foram capturados 1.831 retweets (Figura.5) que, em sua grande maioria, foram motivados pela repetição, às 16h41, da demonstração do exoesqueleto pela TV Globo. Um minuto antes, o perfil 
oficial da emissora (@rede_globo) postou o tweet "Reveja: Jovem paraplégico usa exoesqueleto e chuta bola na abertura da Copa. Disponível em <http://glo. bo/1q8A9oj\#GloboNaCopa>", indicando a matéria já postada pelo perfil @g1. Essa mensagem foi retuitada 233 vezes (5A). A "defesa" das Organizações Globo foi reforçada por novas redes de RTs dos tweets anteriores de @g1 (5B), o que não impediu que críticas à emissora e referências a uma suposta cessão à pressão da internet predominassem o debate nos minutos seguintes. O tweet mais retuitado do intervalo veio do @impedimento, que às 16h43 escreveu "Globo agora dedica um tempo especial a comentar o exoesqueleto. Tem gente de olho nas críticas das redes sociais" (5C). No mesmo sentido, formaram-se redes de RTs em torno dos tweets de @trasel ("Globo se ligou no papelão que fez e está mostrando o vídeo do exoesqueleto agora, em replay.") (5D) e @celsomon ("MOSTRARAM O EXOESQUELETO. PRESSÃO DA INTERNET WINS NOVAMENTE") (5E), entre outros. Segundo tweet de @nostrendsbrasil (5G), a expressão "Agora a Globo" chegou aos Trending Topics Brasil.

Figura 5: Rede de RTs com o termo "exoesqueleto" entre $16 \mathrm{~h} 35$ e $16 \mathrm{~h} 50$ do dia $12 / 05 / 2014$

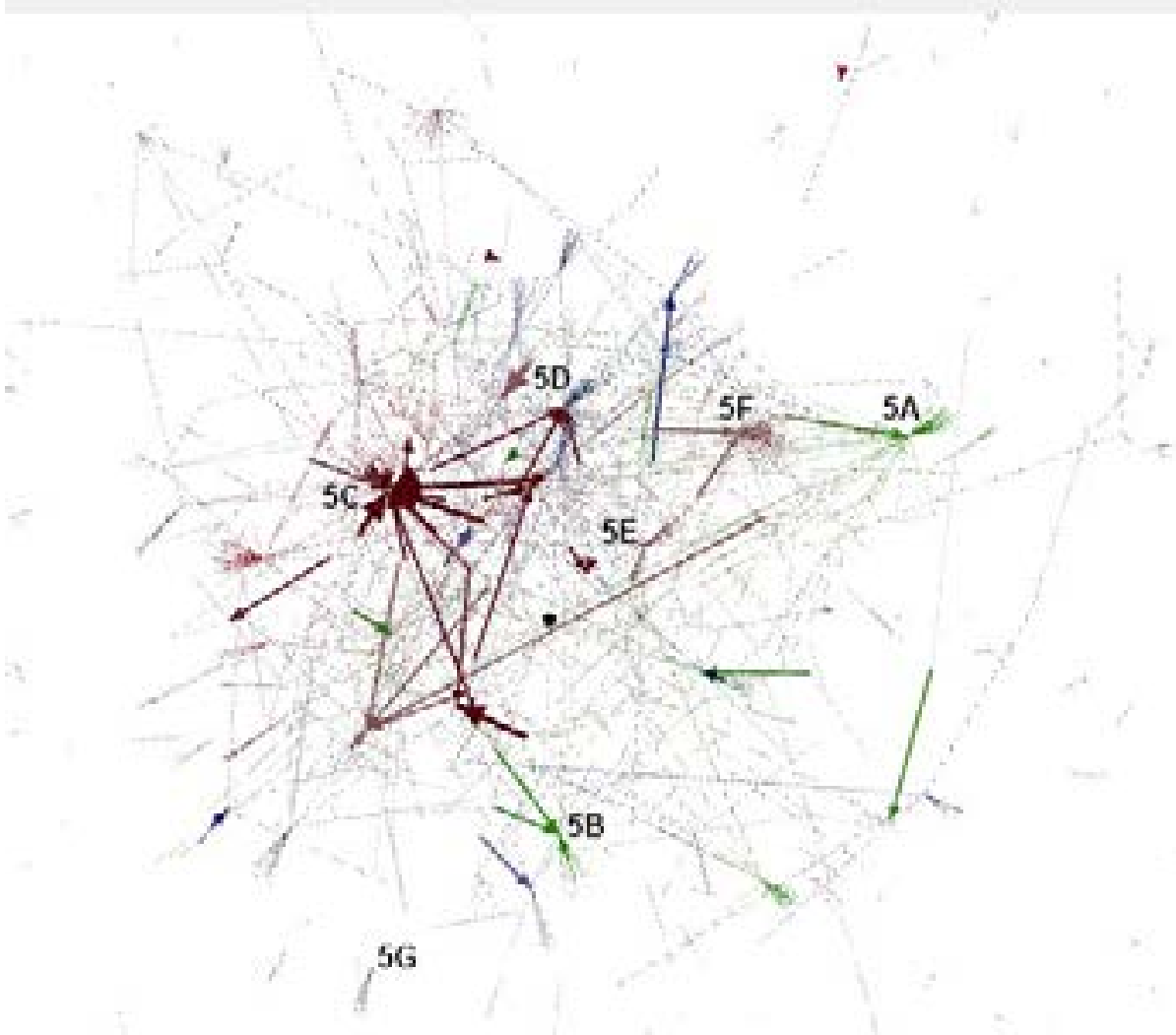

Fonte: Elaboração do autor 
Entre 16h50 e 17h05 - período que compreende o início da partida de abertura da Copa do Mundo - a movimentação de RTs reduz para 699 associações (Figura 6). Identificam-se redes de RTs isoladas e menos densas em torno dos perfis @impedimento (6A) e @oficialjoao (6B), que não postaram novos tweets no intervalo; e de tweets de @gizmodo (6C) e @material_ciencia (6D), divulgavam matérias próprias criticando a transmissão. $\mathrm{O}$ conjunto $6 \mathrm{E}$ representa a rede de RTs em torno do perfil @rafaelmadeira, que publicou um total de seis tweets nonsense sobre o exoesqueleto, antecipando um tom irônico que a subcontrovérsia viria a assumir em seguida, principalmente depois do gol contra do jogador Marcelo na partida da Seleção Brasileira.

Figura 6: Rede de RTs com o termo "exoesqueleto" entre $16 \mathrm{~h} 50$ e 17h05, do dia 12/05/2014

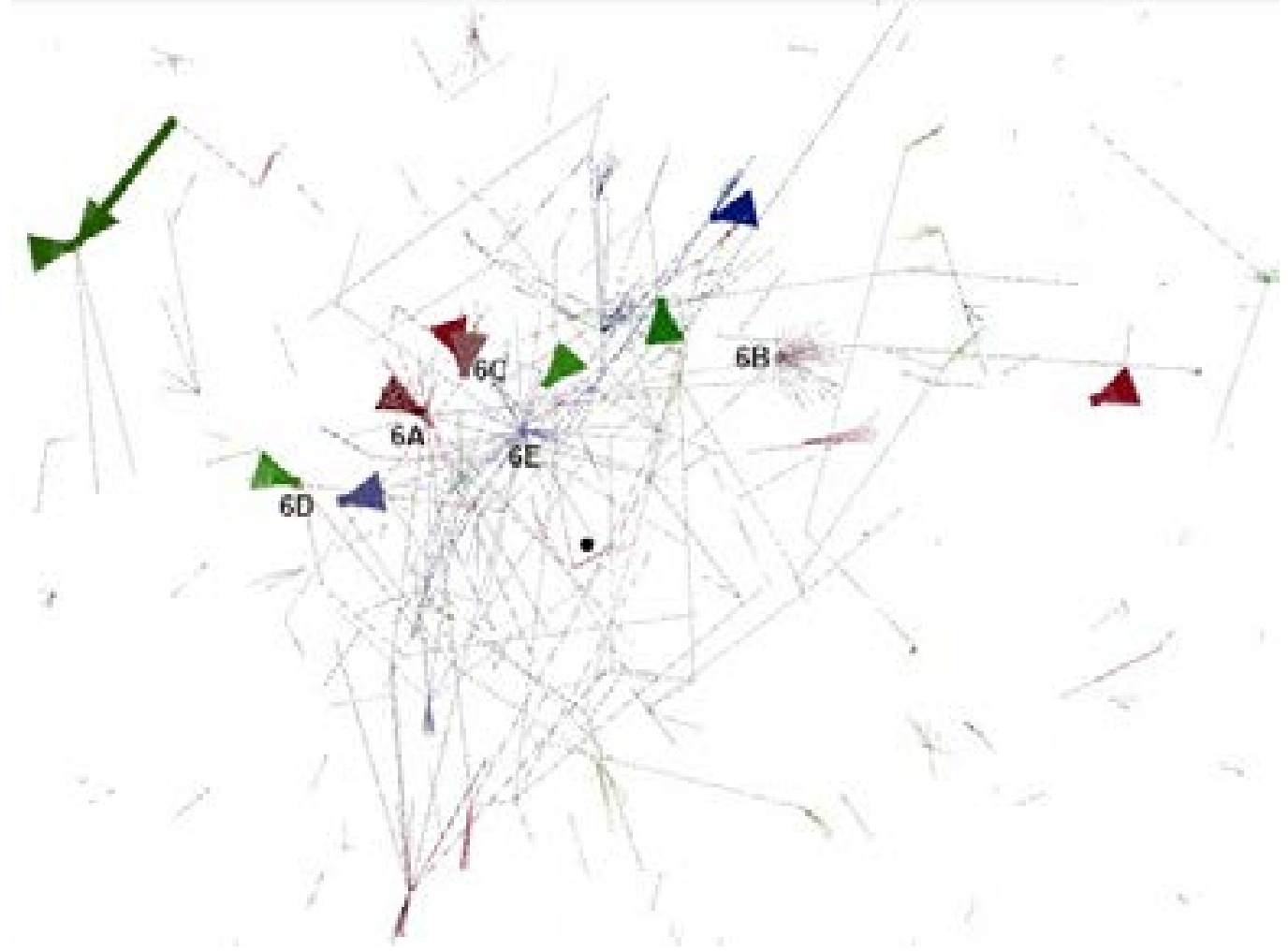

Fonte: Elaboração do autor 


\section{Análise e considerações finais}

Um olhar analítico para as redes de RTs em torno da palavra "exoesqueleto" à luz das discussões conceituais empreendidas ao longo do artigo nos permite fazer algumas análises sobre o desenrolar das associações ao longo da transmissão televisiva, assim como apontar questões a serem aperfeiçoadas em pesquisas futuras.

Um aspecto que chama atenção já na Figura 1 (grafo acumulado) mas se evidencia mais claramente no vídeo e nos grafos com intervalos de 15 minutos é o caráter distribuído das redes de RTs que compõem o dataset. Os perfis citados na apresentação dos dados são mediadores que ajudaram a desencadear redes extensas articuladas por muitos outros mediadores que, em função o "encapsulamento" dos RTs automáticos pela ferramenta, têm seus rastros invisibilizados nos dados coletados. Considerando, no entanto, que a ação é da rede, e não do ator, o que se destaca não são aparentes pontos obrigatórios de passagem, mas a capacidade dessas redes de atrair um conjunto diversificado de perfis. Nesse sentido, ainda que tecnicamente isoladas entre si, as centenas redes de RTs que compõem o dataset analisado culminam em uma ação articulada que ajuda a dar mais alcance e visibilidade ao tema. A situação que melhor ilustra essa característica da formação da rede é o espalhamento rápido e distribuído da fotografia do exoesqueleto chutando a bola. A imagem postada e retuitada por diferentes perfis que, mesmo não se associando diretamente, fizeram emergir uma rede extensa de difusão de uma imagem que, em última instância, comprovava que o experimento científico realmente já havia sido exibido na TV. Já para os perfis ligados às Organizações Globo (@rede_globo e @g1, em especial) o isolamento das redes por eles mobilizadas impediu que a aparente tática de responder às críticas tivesse uma permeabilidade suficiente.

No que tange ao encadeamento temporal da rede analisada, o vídeo produzido evidencia, como esperado, uma lógica de associações muito rápida em torno de alguns tweets (principalmente os mais retuitados), confirmando o caráter emergente das redes de RTs que se formam nessas circunstâncias. Por outro lado, algumas redes de RTs se prolongam por intervalos de mais de 30 minutos (caso da rede em torno do tweet de @vivacqua, o mais popular do dataset). Em outras situações, redes se formam em torno de perfis com muitos seguidores mesmo que o tweet em questão mostre-se claramente "atrasado" - é o caso dos RTs da postagem de @dilmabr sobre a "expectativa" em torno do exoesqueleto publicada quase 40 minutos depois da rápida aparição na TV. Assim, nos parece importante considerar uma certa coexistência da lógica 
instantânea do Twitter com uma temporalidade diferida capaz de manter ou recolocar em pauta um assunto.

As articulações aparentes entre as redes de RTs analisadas e a transmissão televisiva da cerimônia de abertura a pontam uma considerável ressignificação da controvérsia em torno do projeto Andar de Novo. Mais do que uma midiatização dos debates, o que os dados indicam é que a subcontrovérsia "ExoesqueletoTV Globo-FIFA" é predominantemente midiática, isto é, tem na mídia e seus processos tecnopolíticos um eixo decisivo de discussão. Nesse sentido, é bastante sintomático que a "pressão das redes sociais" tenha se concentrado na TV Globo ainda que a geração das imagens da cerimônia de abertura fosse de responsabilidade da FIFA e que o próprio Miguel Nicolelis tenha afirmado pelo Twitter, às 16h26, que as reclamações deveriam ser direcionadas para a entidade internacional ${ }^{10}$. São recorrentes situações em TV Globo se torna um "alvo" dos sistemas emergentes de resposta no Twitter a partir da abertura da caixa-preta das transmissões televisivas, o que pode ser atribuído a uma controvérsia mais duradoura em torno de questões políticas e econômicas que envolvem o principal conglomerado de mídia do país. Nesse sentido, ao se misturar com outros temas controversos (Copa do Mundo, TV Globo etc.), a peculiaridade midiática da subcontrovérsia aqui analisada ao mesmo tempo complexifica as questões políticas, partidárias, sociais etc., que envolvem o projeto Andar de Novo e contamina essas outras controvérsias.

Encerramos o artigo destacando dois dos muitos desafios nos desdobramentos da pesquisa aqui proposta. Ainda que as aproximações entre Twitter e TV sejam bastante intensas, faz-se cada vez mais necessário pensar em conexões intermidiáticas mais complexas, isto é, que envolvam outros ambientes midiáticos considerando suas singularidades e conexões. Além disso, a despeito das diferenças entre as concepções de rede defendidas pela Teoria Ator-Rede e pela Análise de Redes Sociais, consideramos que elas podem oferecer instrumentos e visadas complementares para os estudos de formação de redes em ambientes digitais. Nesse contexto, o desafio que se impõe é a conciliação de métodos quanti e qualitativos que permitam conciliar uma síntese do grande volume de dados e análises que explicitem o caráter dinâmico, processual, não reducionista etc. dos fenômenos sociais e midiáticos, conforme apontam as perspectivas conceituais desenvolvidas pelas teorias (Ator-Rede e dos Sistemas Adaptativos Complexos) que norteiam esta pesquisa.

10 Disponível em: $\leq$ https://twitter.com/MiguelNicolelis/status/477532524919668737>. 


\section{REFERÊNCIAS}

ALVES, Marcelle. A agência de humanos e não humanos na rede Miguel Nicolelis.

Comtempo, São Paulo, v. 6, n. 2, dez. 2014.

BEGUOCCI, Leandro; BURGIERMAN, Denis. Milagre ou Truque? Revista

Superinteressante, p. 40-49. jun. 2014,

BRUNS, Axel e BURGESS, Jean E. The use of Twitter hashtags in the formation of ad hoc publics. In: 6th European Consortium for Political Research General Conference, University of Iceland, Reykjavik. Anais of 6th European Consortium for Political Research General Conference, 2011.

CALLON, Michel. Entrevista: Dos estudos do laboratório aos estudos de coletivos heterogêneos, passando pelos gerenciamentos econômicos. Sociologias, Porto Alegre, ano 10, n.19, p. 302 jan./jun. 2008.

. La dinamica de las redes tecno-economicas. In:THOMAS, Hérnán, BUCH, Alfonso. Actos, actores y artefactos - Sociologia de la tecnologia.

Bernal: Universidade Quilmes, p.147-163, 2013.

CRAWFORD, Cassandra. Actor Network Theory. In: RITZER, George. Encyclopedia of Social Theory. Sage, 2004.

D'ANDRÉA, Carlos. TV + Twitter: reflexões sobre uma convergência emergente. In.: SOSTER, Demétrio; LIMA JR., Walter (org.). Jornalismo digital: audiovisual, convergência e colaboração. Santa Cruz do Sul: Edunisc, p. 43-63, 2011.

. Conexões intermidiáticas entre transmissões audiovisuais e redes sociais online: possibilidades e tensionamentos. In: XVIII Encontro Anual da Compós, Belém (PA). Anais of Conexões intermediárias entre transmissões audiovisuais e redes sociais online: possibilidades e tensionamentos, 2014.

DAYAN, Daniel; KATZ, Elihu. La Historia en Directo: La Retransmisión Televisiva de Los Acontecimientos. Barcelona: Gustavo Gili Editorial, 1995.

DELMAZO, Carol. Natureza, Dança, Futebol e Ciência: conheça detalhes da cerimônia de abertura da Copa. 2014. Portal COPA 2014. Brasília, 9 jun. 2014. Disponível em: <http://www.copa2014.gov.br/pt-br/noticia/natureza-dancafutebol-e-ciencia-conheca-detalhes-da-cerimonia-de-abertura-da-copa>. Acesso em: 10 maio 2015.

DE WOLF, Tom; HOLVOET, Tom. Emergence Versus Self-Organisation: Different Concepts but Promising When Combined. Lecture Notes in Computer Science, v. 3.464, p. 1-15, 2005. 
ESTEVES, Bernardo. O chute. Revista piauí, dez. 2011.

FECHINE, Yvana. Televisão transmídia: conceituações em torno de em torno de novas estratégias e práticas interacionais da TV. In: XXII Encontro Anual da Compós, 2013, Salvador (BA). Anais of Televisão transmídia: conceituações em torno de em torno de novas estratégias e práticas interacionais da TV, 2013.

GRAEFF, E; STEMPECK, M; ZUCKERMAN, E. The battle for Trayvon Martin': Mapping a media controversy online e off-line. First Monday, v.9, n. 2-3, fev. 2014. Disponível em: <http://firstmonday.com/article/view/4947/3821>. Acesso em: 19 jan. 2016.

HEPP, Andreas. As configurações comunicativas de mundos midiatizados: pesquisa da midiatização na era da "mediação de tudo". Matrizes, São Paulo, v. 8, n.1, p. 21-44, jan/jun, 2014.

HOLME, Petter; SARAMAKI, Jan. Temporal Networks. Physics Reports, v. 519, n. 3, p. 97-125, 2012. Disponível em: <http://arxiv.org/abs/1108.1780>. Acesso em: 19 jan. 2016.

JOST, François. Compreender a televisão. Porto Alegre: Sulina, 2007.

LATOUR, Bruno. A Esperança de Pandora: ensaios sobre a realidade dos estudos científicos. Bauro: Edusc, 2001.

LEMES, Conceição. O que há por trás da previsão de fracasso do esqueleto-robô da Copa. Viomundo. Publicado em 6 mai. 2014. Disponível em: <http://www. viomundo.com.br/ denuncias/nicolelis-2.html>. Acesso em: 9 jan.2015.

LEMOS, André. A comunicação das coisas - Teoria Ator-Rede e cibercultura. São Paulo: Annablume, 2013.

MARRES, Noortje. Why Map Issues? On Controversy Analysis as a Digital Method. Science Technology Human Values, v. 40, n. 5, p. 655-686, set. 2015.

VENTURINI, Tommaso. Diving in magma: how to explore controversies with actornetwork theory. Public Understanding of Science, v. 19, n. 3, p. 258-273, maio 2010.

What's in a controversy. Deploying the folds of collective action. Disponível em: $<$ http://pt.slideshare.net/tommasoventurini/3-what-cmdeployingfolds $>$. Publicado em 7 ago. 2013. Acesso em: 9 jan. 2015.

JACOMY, Mathieu e PEREIRA, Debora. Visual Network Analysis. No prelo, 2014. Disponível em: <http://www.tommasoventurini.it/wp/wp-content/ uploads/2014/08/Venturini-Jacomy Visual-Network-Analysis WorkingPaper. pdf> Acesso em: 19 jan. 2016.

e outros. Designing Controversies and their Publics. Design Issues, 2014. 
Recebido em: 21/06/2015.

Aceito em: 14/07/2015.

Endereço do Autor:

Carlos Frederico de Brito d'Andréa <carlosfbd@gmail.com>

Universidade Federal de Minas Gerais

Av. Pres. Antônio Carlos, 6627 - Pampulha

Belo Horizonte - MG

CEP: $31270-901$ 